\title{
Infant exposure to environmental tobacco smoke: Jordan University hospital-based study
}

E. Badran, ${ }^{1}$ A.S. Salhab ${ }^{2}$ and M. Al-Jaghbir ${ }^{3}$

$$
\begin{aligned}
& \text { تعرُّر الرضَّع لدخان التبغ البيئي: دراسة مستندة على مستشفى جامعة الأردن إنبر }
\end{aligned}
$$

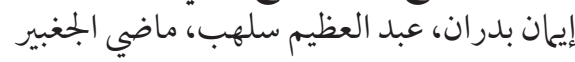

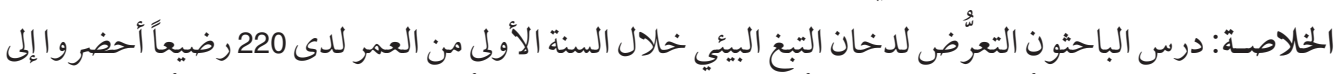

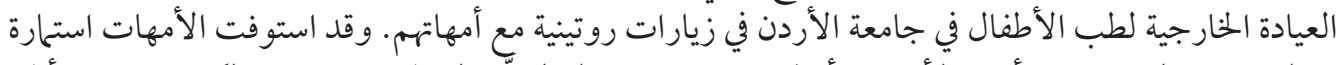

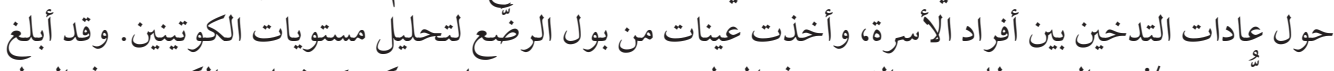

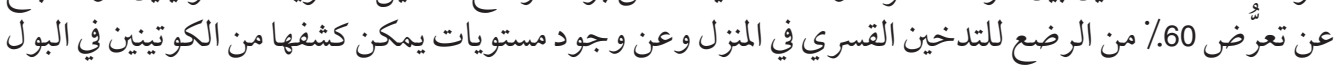

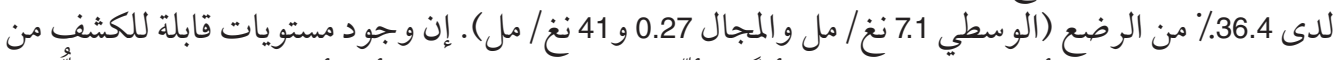

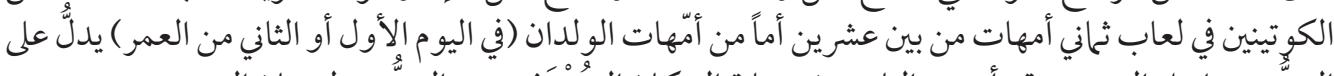

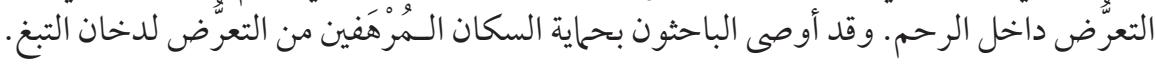

ABSTRACT To study exposure to environmental tobacco smoke during the first year of life, 220 infants attending the outpatient paediatric clinic of the University of Jordan for routine visits with their mothers were recruited to the study. Mothers completed a questionnaire about smoking habits of household members, and urine samples were obtained from infants for analysis of cotinine levels. A total of $60.0 \%$ of infants were reported to be exposed to passive smoking at home and $36.4 \%$ had detectable levels of urine cotinine (mean $7.1 \mathrm{ng} / \mathrm{mL}$, range $0.27-41 \mathrm{ng} / \mathrm{mL}$ ). Detectable saliva cotinine levels in 8/20 mothers of neonates (1-2 days old) suggested in utero exposure. Recommendations are made to protect this vulnerable population from tobacco smoke exposure.

Exposition des nourrissons à la fumée de tabac ambiante : étude en milieu hospitalier à I'Université de Jordanie

RÉSUMÉ Afin d'étudier l'exposition à la fumée de tabac ambiante au cours de la première année de vie, nous avons recruté 220 nourrissons, accompagnés de leur mère, qui se rendaient pour des visites de routine dans le service de consultations externes de pédiatrie de l'Université de Jordanie. Les mères ont rempli un questionnaire sur les habitudes tabagiques des membres du ménage, et des échantillons d'urine ont été prélevés sur les nourrissons en vue d'une analyse des niveaux de cotinine. Au total, il s'est avéré que $60,0 \%$ des nourrissons étaient exposés au tabagisme passif à domicile et que $36,4 \%$ présentaient des niveaux détectables de cotinine urinaire (moyenne $7,1 \mathrm{ng} / \mathrm{ml}$, avec des extrêmes allant de 0,27 à $41 \mathrm{ng} / \mathrm{ml}$ ). Les niveaux de cotinine salivaire détectables chez 8 mères de nouveau-nés (de 1 à 2 jours) sur 20 semblaient indiquer une exposition in utero. Des recommandations sont formulées afin de protéger cette population vulnérable de l'exposition à la fumée de tabac.

${ }^{1}$ Department of Paediatrics; ${ }^{2}$ Department of Pharmacology; ${ }^{3}$ Department of Family and Community Medicine, Faculty of Medicine, University of Jordan, Amman, Jordan (Correspondence to A.S. Salhab: assalhab@ju.edu.jo).

Received: 04/01/05; accepted: 09/08/06

المجلة الصحية لشرق المتوسط، منظمة الصحة العالمية، المجلد الخامس عشر، العدد (، 9 +. 


\section{Introduction}

Infant and early childhood exposure to environmental tobacco smoke is well recognized as a health hazard [1]. Compared to adults, infants are more susceptible to the damaging effects of environmental tobacco smoke. The consequences of prolonged exposure in close proximity to parental smoking are exacerbated by infants' immature immune and pulmonary systems [2], small body size and higher rates of ventilation [3].

Community studies in Europe, United States, Australia and elsewhere in the world have suggested that smoking by mothers and other household members results in increased risk of chronic childhood otitis media, coughs, wheezing, bronchitis, asthma and sudden infant death syndrome (SIDS) [1,4-6]. In the United States of America, studies using biochemically validated data suggest that up to $77 \%$ of infants less than 12 months of age are exposed to environmental tobacco smoke [5,7]. In neighbouring Arab countries such as the Syrian Arab Republic, Lebanon, Saudi Arabia and Egypt, infant exposure to environmental tobacco smoke has also been reported [8-12].

For accurate estimation of infant exposure, measurement of urinary levels of cotinine, the proximate metabolite of nicotine, is considered the most accurate indicator of exposure to environmental tobacco smoke $[7,13]$. Parents' reporting of household smoking offers a further means of assessing infant exposure and provides additional information concerning the circumstances of exposure $[14,15]$.

There have been several investigations of smoking habits in Jordan. The first in 1982 revealed that $71 \%$ and $44 \%$ of Jordanian adult men and women respectively were active smokers [16]. Ten years later Zmeili et al. reported that $72 \%$ of male patients and $21 \%$ of female patients admitted to the department of medicine wards at the University of Jordan hospital over a 1-year period were active smokers, while $25 \%$ of males and $70 \%$ of female patients were passive smokers [17].

Given the lack of data in Jordan about infant exposure to environmental tobacco smoke, the present study aimed to assess the prevalence of infant exposure to environmental tobacco smoke and to measure the cotinine levels in infant urine. In additon, we assessed the extent of exposure by infants to tobacco smoke through information collected by a detailed questionnaire completed by the mothers.

\section{Methods}

Infants were recruited from 2 different settings of the University of Jordan hospital. The first was the outpatient paediatric clinic where infants were taken by their mothers for routine check-ups, immunizations or other medical care. A total of 200 infants aged up to 12 months were recruited from the clinic during the study period, August 2004 to May 2005. The other setting was the neonatal intensive care unit, which was chosen to assess in utero exposure of neonates to tobacco smoke. Here, a total of 20 infants aged 1 to 2 days were recruited during the same study period.

\section{Urine and saliva collections}

Mothers of all the infants were approached by a trained research assistant for their consent to complete a questionnaire and to allow a urine sample to be obtained from their infants. To collect the urine sample, a cotton wool pad was placed in the nappy of each infant [14]. The pad was removed at the conclusion of the questionnaire, duration 10 to 15 minutes. The urine was extracted by compression in a syringe [7]. 
Urine samples were kept frozen at $-20{ }^{\circ} \mathrm{C}$ until analysis.

In addition, 20 saliva samples were collected from the mothers of the neonates only. The collected saliva samples were kept frozen at $-20{ }^{\circ} \mathrm{C}$ until analysis.

\section{Cotinine extraction}

Cotinine from urine or saliva samples was extracted according to the procedure developed by Salhab et al. [18]. Briefly, $1.0 \mathrm{~mL}$ urine, $1.0 \mathrm{~mL} \mathrm{NaOH}(5 \mathrm{~N})$ and $3 \mathrm{~mL}$ methylene chloride were mixed. The mixture was vortexed for 2 min then centrifuged at $1000 \mathrm{rpm}$ for $5 \mathrm{~min}$. The organic layer was pipetted out and the aqueous layer was extracted once more with $3 \mathrm{~mL}$ methylene chloride; then the mixture was centrifuged again. The combined methylene chloride layer was evaporated under a nitrogen stream until dry. The residue was dissolved in $50 \mu \mathrm{L}$ acetone containing $100 \mathrm{pg} / \mu \mathrm{L}$ lignocaine as external standard, then 1 or $2 \mu \mathrm{L}$ of this solution were injected into a gas-liquid chromatograph. The recovery of cotinine under the described conditions was $97 \%$ with a coefficient of variation of $7 \%$.

\section{Cotinine chromatography}

Cotinine extracted from urine or saliva samples was analysed using capillary gas chromatography [19]. Briefly, the analysis was performed with the GC-2010 gas chromatograph (Shimadzu), fitted with fused silica capillary SP-1000 column $(15 \mathrm{~m} \times$ $0.3 \mathrm{~mm}$ i.d.), film thickness $1.0 \mu \mathrm{m}$ (Rhom and Hass). Cotinine was detected with nitrogen-phosphorous detector. The gas flow rates were: air $175 \mathrm{~mL} / \mathrm{min}$, hydrogen $4.5 \mathrm{~mL} / \mathrm{min}$ and helium (carrier + makeup) $30 \mathrm{~mL} / \mathrm{min}$. The temperature of the oven was programmed as follows: initial temperature was $150{ }^{\circ} \mathrm{C}$ for $2 \mathrm{~min}$, then raised to $230{ }^{\circ} \mathrm{C}$ at a rate of $20{ }^{\circ} \mathrm{C}$ per min (kept at $230{ }^{\circ} \mathrm{C}$ for $7 \mathrm{~min}$ ), then raised again at $250{ }^{\circ} \mathrm{C}$ at rate $50{ }^{\circ} \mathrm{C}$ per min (kept $1 \mathrm{~min}$ ). The temperatures of the injector and the detector were $250{ }^{\circ} \mathrm{C}$ and $300{ }^{\circ} \mathrm{C}$ respectively. The retention times for lignocaine, cotinine and nicotine were 6.0, 5.5 and 2.2 min respectively. Under these conditions, the detection limits of nicotine and cotinine were $5 \mathrm{pg}$ and $10 \mathrm{pg}$ respectively.

\section{Environmental tobacco exposure questionnaire}

In addition to obtaining demographic data about the infants and neonates, the questionnaire sought information about the following: parents' occupations, mother's level of education, family income, number of people in the household, infant's current health status (e.g. otitis media, wheezing, etc.), current smoking status of the mother and number of people in the household, including the number of cigarettes smoked per day.

As a follow-up, a telephone interview was carried out 6 months after the initiation of the study in order to ask about the health status of the infants. The telephone interviews were conducted by the research assistant under the direction of the paediatrician (E.B.). Only 181 (82.3\%) of the mothers responded; the remaining 39 $(17.7 \%)$ could not be reached because they had no telephone at home or they had changed address or were absent at the time of the call.

\section{Statistical analysis}

Data are presented as mean and standard error of the mean (SE). The smoking prevalence was calculated and comparisons between data were performed using 2-tailed Student $t$-test. A $P$-value $<0.05$ was considered statistically significant. 


\section{Results}

Table 1 summarizes the demographic characteristics of the 220 infants and neonates who participated in this study; $56.4 \%$ were male and $43.6 \%$ were female. The range of body weight was $0.8-10.7 \mathrm{~kg}$. Most infants $(89.5 \%)$ were breastfed by their mothers.

According to mothers' reports 132 $(60.0 \%)$ of the infants were exposed to environmental tobacco smoke, mostly by household members such as fathers, brothers or sisters and between 1 and 3 smokers were sharing the infant's home. Only $40.0 \%$ of infants were living in a house without any smokers (Table 1). There were 8 mothers who admitted that they smoked.

Table 2 summarizes the extent of exposure to tobacco smoke of the 2 groups of infants. Cotinine was detected in the urine of 72 infants $(36.0 \%)$ and 8 neonates

Table 1 Demographic data and household smoking patterns for the study group of infants and neonates

\begin{tabular}{lc}
\hline Variable & Value \\
\hline No. of infants and neoneates & 220 \\
No. of males/females & $124 / 96$ \\
Age of infants(months) & \\
$\quad$ Mean (SE) & $2.6(2.9)$ \\
$\quad$ Range & $0.03-12$ \\
Body weight of infants(kg) & \\
$\quad$ Mean (SE) & $4.8(2.0)$ \\
$\quad$ Range & $0.8-10.7$ \\
Feeding of infants & \\
$\quad$ No. breastfed & 197 \\
Smokers in the household & \\
$\quad$ No. of mothers smoking & 8 \\
$\quad$ No. of other family members & \\
smoking & \\
$\quad$ No. of households without a & 138 \\
smoker & \\
\hline
\end{tabular}

aSome households had more than 1 smoker. $S E=$ standard error.
(40.0\%). The overall prevalence of tobacco exposure in both groups was $36.4 \%$. The mean level of cotinine in the urine of the neonates was significantly higher than in the infants ( $t$-test, $P<0.05)$. The cotinine levels in the saliva samples of mothers were 1.5-fold higher than the cotinine levels of the neonate urine. Cotinine was detected in the urine samples of 7 neonates of 8 mothers whose saliva samples were cotininepositive. This is evidence of neonatal exposure in utero.

Table 3 summarizes the education level of the infants' mothers. More than $90 \%$ of the mothers were high-school graduates and among these $35 \%$ were university graduates. Mothers of infants passively exposed to tobacco smoke had a similar level of education to mothers of nonexposed infants. The annual income of families was not significantly different between the 2 groups.

Table 4 summarizes the health status of 181 infants as reported by mothers in the follow-up interviews about selected ear, nose and throat complaints. About one-third of smoke-exposed infants had complaints of recurrent cough, wheezing and otitis media (infants may have had more than 1 ailment). The proportion of infants whose mothers reported no complaints was higher in the group not exposed to smoking than the smoking-exposed group.

\section{Discussion}

Infants less than 12 months of age are perhaps the group most vulnerable to the toxic effects of tobacco smoke. Our finding that $36.4 \%$ of infants had detectable levels of cotinine in their urine is therefore of concern. It suggests that existing community education strategies about environmental tobacco smoke exposure at home, especially the environment surrounding infants, are failing to protect this vulnerable group of 
Table 2 Tobacco smoke exposure in infant and neonate groups as detected by the presence of urine and saliva cotinine in mothers

\begin{tabular}{lcc}
\hline Variable & Infants & Neonates \\
\hline Total no. in study & 200 & 20 \\
Age range & $0.23-12$ months & $1-2$ days \\
No. of mothers smoking & 7 & 1 \\
Urine cotinine (infants) & & \\
$\quad$ No. with cotinine & 72 & 8 \\
$\quad$ Mean (SE) cotinine level $(\mathrm{ng} / \mathrm{mL})$ & $7.1(0.8)$ & $12.5(2.6)^{*}$ \\
$\quad$ Range $(\mathrm{ng} / \mathrm{mL})$ & $0.27-41$ & $1.97-21.5$ \\
Saliva cotinine $($ mothers) & & 8 \\
$\quad$ No. with cotinine & 0 & $18.7(4.3)$ \\
$\quad$ Mean $(\mathrm{SE}) \mathrm{cotinine} \mathrm{level}(\mathrm{ng} / \mathrm{mL})$ & - & $5.8-42.2$ \\
Range $(\mathrm{ng} / \mathrm{mL})$ & - & \\
*P $<0.05$. & &
\end{tabular}

Table 3 Mother's educational level and annual family income for infants exposed and not exposed to environmental tobacco smoke

\begin{tabular}{lccc}
\hline Variable & $\begin{array}{c}\text { Smoking- } \\
\text { exposed } \\
(\boldsymbol{n}=\mathbf{8 0})\end{array}$ & $\begin{array}{c}\text { Not smoking- } \\
\text { exposed } \\
(\boldsymbol{n}=\mathbf{1 4 0})\end{array}$ & $\begin{array}{c}\text { Total } \\
(\boldsymbol{n}=\mathbf{2 2 0})\end{array}$ \\
\hline Mother's level of education [No.(\%)] & $32(40.0)$ & $45(32.0)$ & $77(35.0)$ \\
$\quad$ University & $22(27.5)$ & $35(25.0)$ & $57(25.9)$ \\
$\quad$ Diploma & $23(28.8)$ & $45(32.1)$ & $68(30.9)$ \\
$\quad$ High school & $3(3.8)$ & $15(10.7)$ & $18(8.2)$ \\
$\quad$ Less than high school & & & - \\
Annual income of the family & 2284 & 2738 & - \\
(Jordanian dinar) & & & \\
\hline
\end{tabular}

$\mathrm{n}=$ total no. of infants.

Table 4 Mothers' reports of ear, nose and throat complaints in infants exposed and not exposed to tobacco smoke $(n=181)$

\begin{tabular}{lccccc}
\hline Complaint & \multicolumn{2}{c}{$\begin{array}{c}\text { Smoking-exposed } \\
(\boldsymbol{n}=\mathbf{6 5})\end{array}$} & $\begin{array}{c}\text { Not smoking-exposed } \\
(\boldsymbol{n}=\mathbf{1 1 6})\end{array}$ & $\begin{array}{c}\text { Total } \\
(\boldsymbol{n}=\mathbf{1 8 1})\end{array}$ \\
& No. & $\%$ & No. & $\%$ & No. \\
\hline Recurrent cough & 23 & 35.4 & 40 & 34.5 & 63 \\
Wheezing & 23 & 35.4 & 39 & 33.6 & 62 \\
Otitis media & 16 & 24.6 & 29 & 25.0 & 45 \\
No complaint & 23 & 35.4 & 54 & 46.6 & 77 \\
\hline
\end{tabular}

$\mathrm{n}=$ total no. of infants.

المجلة الصحية لشرق المتوسط، منظمة الصحة العالمية، المجلد الخامس عشر، العدد (، 9. ب 
the population. Furthermore, the finding of tobacco smoke exposure in 8 out of 20 neonates who were less than 48 hours of age is alarming. This is strong evidence that those neonates were exposed to tobacco smoke by mothers during pregnancy. Again, this suggests that physicians are failing to educate pregnant women not to smoke at least during pregnancy. This finding warrants further investigation in the future.

In our study, the prevalence of raised cotinine levels was $36.4 \%$ among infants up to 12 months, which is in agreement with the reported prevalence among passivesmoking infants in Australia [20]. Furthermore, similar results have been reported by neighbouring countries such as Egypt, Syrian Arab Republic, Lebanon and Saudi Arabia [8-12]. In contrast, the prevalence of exposure in this study is lower than that reported previously in the United States of America using the biomarker cotinine, which suggested that up to $77 \%$ of infants less than 12 months of age were exposed to environmental tobacco smoke $[5,6]$.

The mothers' reports revealed that $60.0 \%$ of infants were living with household smokers. This finding is in agreement with our earlier report [17] and the results of other researchers in different countries. Smoking in the presence of infants by mothers, fathers, sisters and brothers and other visitors to the family needs to be modified. Many of the mothers in our study were university graduates and more than $90 \%$ of mothers had graduated from high school. This good level of education should facilitate educational efforts to tackle the problem of smoking in families in order to protect infants, children and others from tobacco smoke.

The results of this study failed to correlate the extent of tobacco smoke exposure with certain infant diseases. This may be due to the small sample size of this study
(220 infants). However, in the literature, it is documented that exposure to parental smoking after birth exacerbates asthma, pneumonia, lower respiratory tract infections, wheezing, meningitis, SIDS, and eye and ear problems [21]. Further, it is estimated that more than 20000 children are hospitalized annually for respiratory illness caused by parental smoking and over 1000 infants die from such health complications [22]. Also, the correlation of environmental tobacco smoke and health diseases such as asthma, cough, wheezing and otitis media, has been reported by several researchers in the Eastern Mediterranean Region [9,10].

The role of paediatricians in reducing tobacco exposure in children is important since adverse health effects are often observed in very young children, including diseases primarily caused by environmental tobacco smoke exposure such as attenuated lung growth, shortness of breath, exacerbation of asthma, respiratory distress, increased incidence of ear infection, and SIDS. Paediatricians may play a leadership role in protecting young people from such ailments because they are the first physician to deal with childhood diseases [23].

A number of issues need to be considered when interpreting the results of this study. First, given the use of convenience sampling from one hospital setting, care should be taken when generalizing to other populations. Secondly, it is difficult to compare the results of tobacco exposure in utero by mothers in neonates (less than 2 days old) with other infants exposed to environmental tobacco smoke. Thirdly, the detection of cotinine in 8 out 20 saliva samples from mothers puts the credibility of mother's reports of smoking in doubt and suggests that it may be necessary to obtain biological samples from mothers in order to evaluate infant tobacco smoke exposure. 


\section{Recommendations}

Based on the results of our study, the following actions are recommended to reduce the level of infant exposure to smoking in Jordan:

- Increase women's awareness about the dangers of smoking during pregnancy.

- Increase parental knowledge about how to reduce infant exposure to environmental tobacco smoke.

- Change parents' pattern of smoking behaviour around infants.
- Establish community education strategies, e.g. smoke-free policies on public transport and in child-care centres.

\section{Acknowledgements}

This research was funded by the deanship of research through grant number 856/2004. The authors gratefully acknowledge Mrs Feryal Mubarak and Mrs Suha Al-Rahma for their skilful technical help and Mrs Wafa Al-Shaer for her excellent secretarial work.

\section{References}

1. National Health and Medical Research Council. The health effects of passive smoking. Canberra, Australian Government Publishing Service, 1997.

2. US Environmental Protection Agency. Respiratory health effects of passive smoking: lung cancer and other disorders. Washington, US Government Printing Office, 1992.

3. Willers $\mathbf{S}$ et al. Urinary cotinine in children and adults during the after semiexperimental exposure to environmental tobacco smoke. Archives of environmental health, 1995, 50:130-8.

4. Strachan DP, Cook DG. Parental smoking, middle ear disease and adenotonsillectomy in children. Thorax, 1998, 53:50-6.

5. Greenberg RA et al. Passive smoking during the first year of life. American journal of public health, 1991, 8:850-3.

6. Lund KE et al. To what extent do parents strive to protect their children from environmental tobacco smoke in the Nordic countries? A population based study. Tobacco control, 1998, 7:56-60.

7. Chilmonczyk BA et al. Environmental tobacco smoke exposure during infancy. American journal of public health, 1990, 80:1205-8.
8. Maziak W. Smoking in Syria: profile of a developing Arab country. International journal of tuberculosis and lung disease, 2002, 6(3):183-91.

9. Maziak W, Mzayek F, Al-Musharref M. Effects of environmental tobacco smoke on the health of children in the Syrian Arab Republic. Eastern Mediterranean health journal, 1999, 5(4):690-7.

10. Tamim $\mathrm{H}$ et al. Exposure of children to environmental tobacco smoke (ETS) and its association with respiratory ailments. Journal of asthma, 2003, 40(5):571-6.

11. El-Ansari W. Passive smoking in children: facts and public health implications. Eastern Mediterranean health journal, 2002, 8(1):74-8.

12. Rashid M, Rashid H. Passive maternal smoking and pregnancy outcome in a Saudi population. Saudi medical journal, 2003, 24(3):248-53.

13. Benowitz NL. Cotinine as a biomarker of environmental tobacco smoke exposure. Epidemiologic reviews, 1996, 18:188204.

14. Matt GE et al. Measuring environmental tobacco smoke exposure in infants and young children through urine cotinine and memory-based parental reports: empirical 
findings and discussion. Tobacco control, 1999, 8:282-9.

15. Bauman KE, Greenberg RA, Haley NJ. A comparison of biochemical and interview measures of the exposure of infants to environmental tobacco smoke. Evaluation and the health professions, 1989, 12:179-91.

16. Salhab AS et al. Detection of nicotine and cotinine in maternal and cord blood and induction of 7-ethoxycoumarine O-deethylase in placenta. Dirasat, medical and biological sciences, 1996, 23(2):88-94.

17. Zmeili $S$ et al. Clinical evaluation of a new A.S. mouth wash 881010 as an antismoking agent: a placebo-controlled doubleblind trial. International journal of clinical pharmacology and therapeutics, 1999, 37(1):41-50.

18. Salhab AS et al. A study on smoking in Jordan. Dirasat, 1984, 9 (2):257-68.
19. Zmeili SM et al. Cigarette smoking in Jordan in some Jordanian patients. Dirasat, 1992, 19B(3):253-60.

20. Daly JB et al. Infant exposure to environmental tobacco smoke: a prevalence study in Australia. Australian and New Zealand journal of public health, 2001, 25(2):132-7.

21. Greenberg RA et al. Ecology of passive smoking by young infants. Journal of pediatrics, 1989, 114(5):774-80.

22. Li JS et al. Meta-analysis on the association between environmental tobacco smoke (ETS) exposure and prevalence of lower respiratory tract infection in early childhood. Pediatric pulmonology, 1999, 27(1):5-13.

23. Risa JS et al. The pediatrician's role in reducing tobacco smoke exposure in children. Pediatrics, 2000, 106(5):1-29.

\section{Release of the Arabic edition of MPOWER}

The Arabic edition of the MPOWER report was published in October 2008. The report presents the first comprehensive data on global tobacco use and control efforts. It shows that currently most countries in the world do not have adequate information or policies about tobacco use and trends, and 6 new policies are recommended for immediate adoption by countries. These policies will support the full implementation of WHO FCTC. In other countries where FCTC is not yet officially adopted they will pave the way for its adoption. More information about this publication is available at: http://www.emro.who.int/tfi/tfi.htm 